The International Journal of
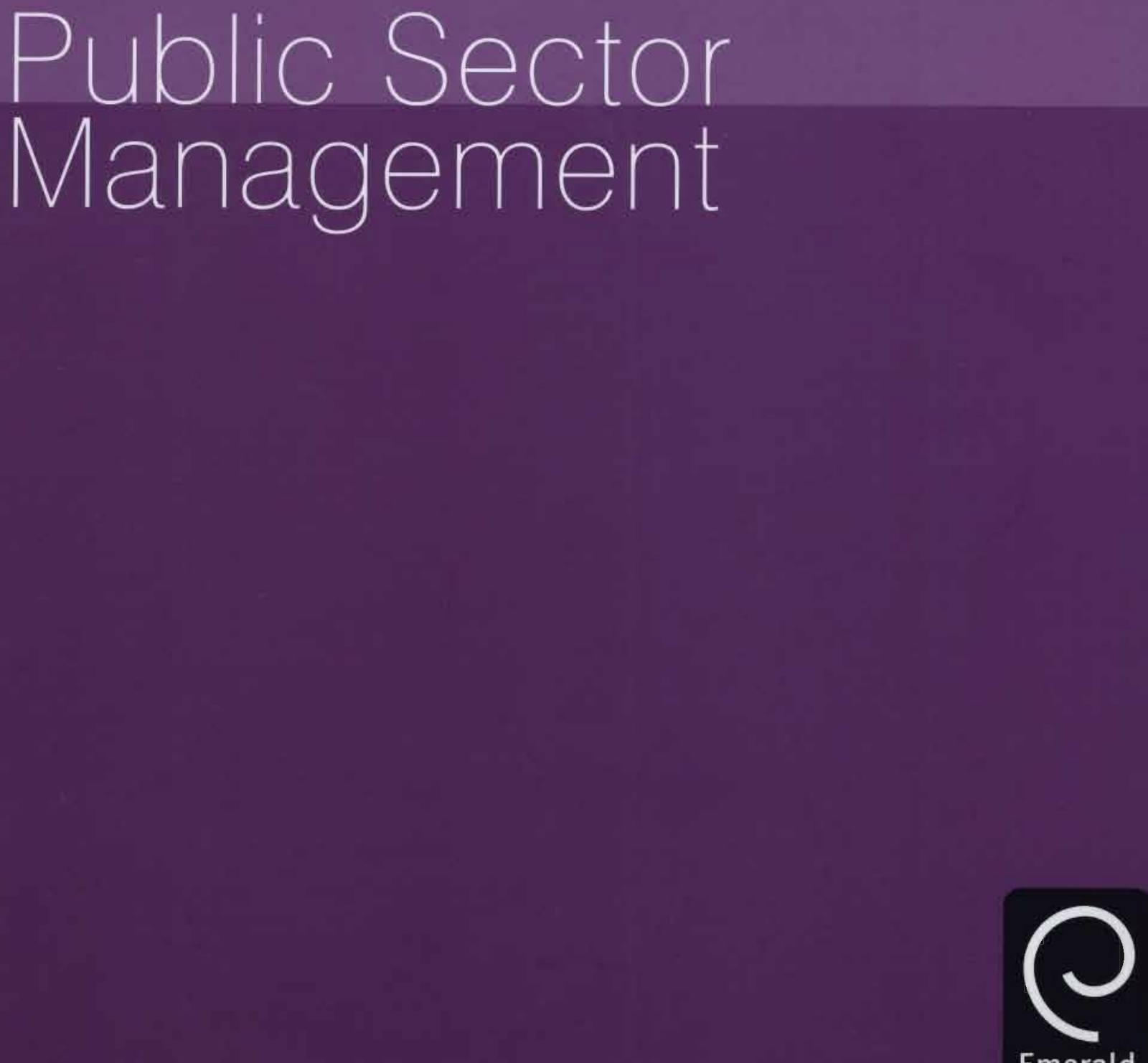

Emerald 
The Emerald Research Register for this joumal is available at www.emeraldinsight.com/researchregister
The current issue and full text archive of this journal is available at www.emeraldinsight.com/0951-3558.htm
IJPSM

17,1

48

\section{Performance appraisal decision in Malaysian public service}

\author{
Rusli Ahmad \\ Universiti Malaysia Sarawak, Kota Samarahan, Malaysia, and \\ Nur Azman Ali \\ School of Management, University of Bradford, Bradford, UK
}

Keywords Performance appraisal, Decision making, Pubäc services, Malaysia

Abstract This article explores raters' understanding on the decision-making process in the public service performance appraisal system (PAS) by looking at the cognitive processing models (CPM) steps involved Presents the results of semi-structured cognitive mapping interviews undertaken with novice raters in the Malaysia public service (MPS) context. Interviews were conducted using cognitive mapping protocol. The resultant causal cognitive maps explored findings from CPM applied in appraisal decision making. Explains the performance appraisal process and theoretical framework for the CPM. From the research findings, it is clear that raters recognised the CPM steps in their performance appraisal practice. The study also identifies individual differences in novice raters' $C P M$ in terms of concepts and complexity. The findings are used to validate the CPM concepts suggested in related literature. Finally, the study discusses the implications of CPM in a broader context of performance appraisal decision-making process.

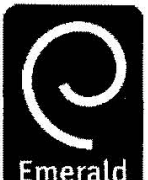

The International Journal of Public Sector Management vol 17 No. 1,2004 pp. 48.64

C) Emerald Group Publishing Limited $0951-3558$

DOI 10.110609513550410515565 